\title{
Situational Judgment Tests and Transformational Leadership: An Examination of the Decisions, Leadership, and Experience in Undergraduate Leadership Development
}

\author{
Greg Grossman \\ Lead Faculty \\ Organizational Leadership \\ Colorado State University Global Campus \\ Ruth Sharf \\ Affiliate Professor \\ School of Criminal Justice \& Social Sciences \\ Tiffin University
}

\begin{abstract}
We examined a large multi-year undergraduate leadership development program (LDP) across seven universities and used an integrated framework of transformational leadership and situational judgment tests (SJTs) during a critical and formative period of leadership development. This study was the first to show a significant relationship between experience and transformational leadership style in students in an undergraduate LDP using SJTs and the multifactor leadership questionnaire (MLQ). The results showed that greater experience was positively related to increased transformational leadership style and that high overall decision scores were indicated in all groups of students with varying leadership styles and varying experience levels and decision abilities. The study findings and implications are discussed, along with recommendations for leadership educators to develop decision quality in LDPs.
\end{abstract}

\section{Introduction}

Educators and researchers continue to struggle with how best to address the effects of information overload and reduced decision timeframes in difficult postmodern settings as they assess (and reassess) traditional leadership development methods that have been developed to meet such demands (Brungardt, Greenleaf, Brungardt, \& Arensdorf, 2006; Davenport, 2014; Louvieris, Gregoriades, \& Garn, 2010). Poor decision skills, heterogeneous experience levels, and inadequate training might result in inferior performance by leaders in such environments. Leadership styles and effectiveness have been studied in the past, but the current study is the first to use situational judgment tests (SJTs) to examine and offer insight into the decision quality, experience, and leadership styles of students in an undergraduate leadership development program (LDP) before leaders assume their duties. The current study examined the effects of leadership style and experience on decision quality in a large multi-year undergraduate LDP spanning seven universities with defined program objectives that aim to prepare leaders for difficult situations. The study used an integrated and practical framework consisting of transformational leadership theory and SJTs of decision quality (Bass \& Avolio, 2004; Bass, Avolio, Jung \& Berson, 2003; McDaniel, Psotka, Legree, Yost, \& Weekley, 2011). Although 
research on undergraduate LDPs is somewhat limited, an integrative approach using SJTs in a context-specific examination of leadership styles and decision quality has been previously employed with some success (Peus, Braun, \& Frey, 2013).

Instructors of LDPs can improve training and training outcomes before students assume actual leadership roles if these instructors can acquire a deeper understanding of the effects of leadership style and student experience on decision quality during critical and formative periods of students' leadership development. Although ongoing leadership development throughout a leader's career is certainly important, the feedback and training a leader receives over the course of his or her career may come too late to be applied in the near-term. Unprecedented challenges await the new graduates of today's LDPs (Leonard, Polich, Peterson, Sortor, \& Moore, 2006), and early testing and assessment of undergraduate students should be conducted and documented to measure the impact of LDPs on leadership development (Avolio, Walumbwa, \& Weber, 2009; van Schalkwyk, 2010). A leader must be prepared to move into difficult leadership positions after graduation and to lead in any number of critical roles, including those with complex geopolitical and multi-cultural features in unique and sometimes dangerous contexts (Hannah, Campbell, \& Matthews, 2010). Thus, a primary objective of the LDP is to produce young men and women who have acquired enough experience to make quality decisions and employ effective leadership approaches upon graduation. An LDP can provide two to four years of developmental experiences and training during the young leader's formative undergraduate educational preparation to improve leadership performance and to prepare young leaders for success in such environments (Foster \& Farquharson, 2011).

LDP graduates often become leaders in support of national defense. In addition, many go on to serve in roles - including corporate, educational, and government positions - for which the leadership talents and traits they have developed are well-suited (Pema \& Mehay, 2012). Leaders who can reason with and effectively influence others are sought after for their ability to elicit profound outcomes from organizations, groups, and subordinates. Much can be learned from examining the leadership, experience, and decision-making processes characterizing those who must handle unconventional postmodern decision scenarios (Ojiako, Johnson, Chipulu, \& Marshall, 2010). Using assessments to examine such variables and to thereby improve performance is an important step for many who seek empirical support in this area of study.

Billions of dollars are spent in program administration, support, and scholarships in such LDPs to develop and refine the abilities of these students before they assume leadership roles (Wardynski, Lyle, \& Colarusso, 2010). In conjunction with hundreds of universities located in distinct geographical regions, between 4,500 to 7,000 student leaders graduate from undergraduate LDPs annually (Ngaruiya, Knox Velez, Clerkin, \& Taylor, 2014). A large LDP spanning two states was examined in the current research study. LDP administrators, educators, and researchers may benefit from the knowledge and pertinent empirical results of a study conducted in such a manner and that employed SJTs and the Full Range of Leadership (FRL) theory (Bass, 1985; Tucker, Gesselman, \& Johnson, 2010; Tucker, Pleban, \& Gunther, 2010).

Improving leader performance and decision quality requires an integrated approach to assessment and evaluation in which the instructors must adapt to individual student differences and use assessment tools to determine and evaluate behavioral dimensions to improve 
effectiveness and to achieve the LDP's stated outcomes (Patrick, Scrase, Ahmed, \& Tombs, 2009). For leaders to make better decisions, they must have better decision quality and an effective leadership style. Studies of transformational leadership have shown it to be a highly effective leadership style, and decisions based on transformational leadership style should be considered in context (Mannheim \& Halamish, 2008). However, transformational leadership and other leadership styles have not been differentiated based on experience in the LDP context. Several variables were chosen for use in the study after examining the literature to focus on decision quality, leadership style, and experience. Decision quality is a focal point in training leaders and to prepare them for future leader roles (Funk, 2002; West, 2012). Leadership style and specifically transformational leadership style - and the experience of the participants, were examined to determine whether there were significant differences based on experience. These variables were carefully chosen from the principal objective outcomes of the LDP because leaders must be able to consciously regulate their own cognitive processes when making decisions to influence others when circumstances are not ideal (Firing, Karlsdottir, \& Laberg, 2009). Modern leaders must make high-quality decisions with less than adequate information upon which to base those decisions and must avoid personal preconceptions and bias (Ahn, Ettner, \& Loupin, 2011). With this precept in mind, the curriculum of the LDP encompasses classroom instruction and leadership laboratory scenario training, and participants are evaluated using preferred leadership behaviors to develop leadership and decision-making capabilities as they gain practical experience before assuming actual leadership roles. The context in which the leader's performance is examined is important, and situational differences can necessitate adapted and varying responses, in addition to the use of leadership styles based on interaction (Bass, 1985). In the current study, students in the LDP were examined using established methods that tested their abilities in contextual scenarios similar to those in which they will perform in their future leadership roles.

Decision Training and Situational Judgment Tests. The use of difficult decision scenarios in training is a generally acknowledged approach to ensure leadership is developed and studied in context (Brocato, Jelen, Schmidt, \& Gold, 2011). Improved performance from and decisions by those who use the transformational leadership style have been highlighted in studies in which leadership styles were examined in difficult situational decision scenarios (Dvir, Eden, Avolio, \& Shamir, 2002; Piccolo \& Colquitt, 2006; Walumbwa, Avolio, \& Zhu, 2008). One primary concept of the LDP is to challenge the leader with an array of difficult and varying appropriate contextual scenarios to force the leader to adapt, while making the best decision possible under the circumstances. Student leaders should have had the regular opportunity to identify and examine their styles and preferences in training prior to assuming their duties. Future leaders must be able to consciously regulate their own cognitive process when making decisions in which circumstances are not ideal and when support from large staffs to make decisions is unavailable (Firing et al., 2009).

The leadership decision-training scenario is an established technique used to evaluate leadership behavior and performance, which is employed with SJTs (Tucker et al., 2009; Tucker et al., 2010). Practitioners have a number of leadership models and theories available to them from which to choose, but when applying such theories in an LDP, many have difficulty assessing and applying theory outside of the situational or scenario approach used to analyze leadership (Seiler \& Pfister, 2009). For example, a stressful exercise can be employed in which 
students assume the role of a captured leader (a not so unrealistic scenario for a leader in today's world) and are forced to make an ethical decision about revealing sensitive information (Olsen, Eid, \& Johnson, 2006). Notably, decisions in difficult scenarios in which the use of transformational leadership may predominate are not universal but are related in these types of stressful contexts and situational environments (Mannheim \& Halamish, 2008; Tucker, et al., 2010).

Transformational Leadership. Notably, the transformational leader is of particular interest for those who rely on well-trained leaders to guide teams and organizations to achieve expected (and increasingly higher) levels of performance. Transformational leadership (TL) in leadership training and leader development has significant value with regard to predicting performance (Bass et al., 2003; Bass \& Bass; 2008). TL has been identified as particularly effective for making decisions and for leading teams to higher performance levels and is thus taught in the LDP (Avolio, et al., 2009). In seminal studies, LDPs were used to validate early versions of the multifactor leadership questionnaire (MLQ) that is used to assess leadership styles (including those of many recent graduates of LDPs) in which leaders were rated as more transformational and performance indicators were more effective at home base and in 34 simulated scenario training exercises (Bass et al., 2003; Bass \& Avolio, 2000). The instruments' validity and application have been refined and expanded to be generalizable to numerous industries and disciplines, although transformational leadership and transactional leadership behaviors that may be effective in one situation may not be equally effective in all contexts (Hargis, Watt, \& Piotrowski, 2011). Leadership style was hypothesized in the proposed study to influence higher quality decisions in training since optimal leadership profiles are more transformational and are associated with better outcomes (Bass \& Bass, 2008). Transformational leadership theory and decision-making efforts are fundamental to improving team effectiveness (Zhang \& Peterson, 2010).

Experience. Experience is an established and important factor in leadership development, and developmental experiences can be used to enhance and teach leadership in specific contexts in an LDP (Keating, Rosch, \& Burgoon, 2014; Shepherd \& Horner, 2010). Student leaders are developed, and experiences (both good and bad) are obtained in the classroom and by using developmental scenarios introduced over years of participation in the LDP via a continuum of overlapping and progressive stages with defined criteria (Brungardt, 1996; Shepherd \& Horner, 2010). In the current study, students' experience levels were determined by year of participation in the LDP to differentiate students at various stages of leadership development. Those in their freshman or sophomore year were categorized as nonexperienced, whereas those who were juniors or seniors were categorized as experienced. Context-specific assessments, such as those used in this study, are critical to informing our efforts in LDPs to improve decision quality training, behavior, and decision making (Westaby, Probst, \& Lee, 2010).

In sum, drawing upon research and theory with regard to decision quality and training, SJTs, and transformational leadership, we will hypothesize and test for the significant effects of leadership styles and experience and for any interaction effect on decision quality. In addition, we will determine whether there are differences in the transformational leadership styles of nonexperienced and experienced students. 


\section{Research Questions}

To investigate the problem presented, at the outset of the investigation, several research questions were developed to gather data. The following research questions were used to address the issues presented:

1. To what extent, if any, are there differences between experienced and nonexperienced leadership students (as determined by the number of years in the LDP) in transformational leadership style scores (as measured by the MLQ-5X)?

2. To what extent, if any, does the experience level of leadership students (as determined by the number of years in the LDP) affect decision quality (as measured by SJTs)?

3. To what extent, if any, do the leadership style scores (as measured by the MLQ-5X) of leadership students in the LDP affect decision quality (as measured by SJTs)?

4. To what extent, if any, does leadership student experience (as determined by the number of years in the program) interact with student leadership style (as measured by the MLQ-5X) on decision quality (as measured by SJTs) in the LDP?

\section{Methods}

Sample. The sample was obtained from a population of 636 male and female students ranging in age from 18 to 28 years old and who were participating in the undergraduate LDPs at seven universities in two states. The population of students in the LDPs consisted of 221 freshmen, 151 sophomores, 144 juniors, and 120 seniors, adding up to the above-mentioned 636 students as of the date the study data were collected. A total of 211 students responded to the questionnaire, and, 173 of those completed the questionnaire, although 12 were excluded based on established exclusion criteria in which the student indicated prior participation in an equivalent advanced leadership program. Thus, a sample size of $N=161$ students was used. The average age of participating students in the study's sample was 20 years old $(M=20.44$, $S D=2.91)$. The average age of the experienced students $(M=19.91, S D=2.28)$ was the same as the average age of the non-experienced students $(M=19.87, S D=2.35)$. Of the participants, 70 students indicated that they had military service, which ranged from attending basic training to serving more than four years. Experienced students had between two to three years of experience in the LDP, whereas nonexperienced students ranged from no experience to two years of experience in the LDP.

\section{Instruments and Operational Definitions.}

MLQ-5X. The participants were categorized based on the highest leadership style scored from the MLQ-5X as transformational, transactional, or passive-avoidant (Bass \& Avolio, 2004). The MLQ-5X consists of 45 items with strong established validity and reliability (Bass \& Avolio, 2004). No participants' scores involved in the study indicated the use of a passive-avoidant style. The transformational leadership style scores of all participants from the MLQ-5X were used for the initial part of the study. Transformational leadership was measured using established scoring methods based on 
five subscales, and the range of scores were measured on a 5-point Likert scale ranging from 0 (not at all) to 4 (frequently if not always) (Bass \& Avolio, 2004). In the range of scores, higher scores indicated more frequent use of transformational leadership style and lower scores indicated less frequent use of transformational leadership style.

Experience Level. Participants were categorized by experience based on years in the LDP and self-reported demographic data. Students in their junior or senior years in the LDP were categorized as experienced. Students in their freshman and sophomore years were categorized as nonexperienced. The responses were gathered from the respondents based on demographic questions that accompanied the questionnaire.

SJT. Decision quality was assessed by responses to a SJT with difficult decision scenarios, and the scores were assessed based upon a scoring key established by an expert panel with between 17 to 25 years of leadership experience and by using questions based on a Likert-type scale ranging from 1 (very poor quality decision) to 5 (very good quality decision) (McDaniel et al., 2011). Two methods from the literature were considered for establishing the scoring key: consensus scoring and expert scoring (McDaniel et al., 2011; Peus et al., 2013). The expert scoring approach was chosen (over the consensus scoring approach), and pursuant to it, overall correct answers are based on the outcomes, as the design involved leaders in an LDP who may or may not have possessed the requisite experience to effectively judge the scenarios. The expert scoring approach worked as proposed, and a clear consensus was established for each of the differential responses to the scenarios. To establish clear consensus on wording effectiveness and to improve reliability and validity, multiple difficult scenarios were used based on both training scenarios employed in development course training and on recommendations from the expert panel (Tucker et al., 2009; Tucker et al., 2010). Scores from the scenarios were averaged, and overall scores closer to 1 indicated a leader who made fewer high-quality decisions, and scores closer to 5 indicated a leader who made more high-quality decisions.

Procedure. Participants were recruited for voluntary participation by an email invitation that directed them to complete the informed consent form and a self-administered questionnaire consisting of a series of demographic questions, the MLQ-5X (to measure leadership style) and the SJTs (to measure decision quality). In addition, the study was advertised in the administrative common areas at the campuses of the universities involved over the same period of time in which the survey was offered concurrently to students at all levels of participation at each of the university LDPs. The demographic questions were used to establish the year of participation in the LDP and were included in the first portion of the questionnaire. Then, the student completed the MLQ-5X, and thereafter the combined questionnaire included the SJT scenario questions. The study was formulated as a comparative design to examine the effects of experience and leadership styles on decision quality and to determine whether experienced and non-experienced students presented differences in transformational leadership style.

The study design and methodology were approved by all the institutional review boards at the universities involved, and the study was determined to have minimal risk. Any residual risk was mitigated using an informed consent notification form in which potential participants 
were informed of the nature of the study and asked to complete an online questionnaire. To further ensure confidentiality, only pertinent demographic data were gathered, and participants' responses were assigned a code, and no identifying data were either stored or used.

\section{Results}

In the first portion of the study, an independent sample t-test was performed to address the first research question, and tests for violations of the assumptions associated with the transformational leadership style data were conducted. An inspection of a boxplot was assessed to determine whether there were outliers for values greater than 1.5 box-lengths from the edge of the box, and no outliers were indicated. Normality was assessed using Shapiro-Wilk's test, and the data were found to be normally distributed $(p>.05)$. Levene's test for equality of variances was used to assess homogeneity, and the test was not statistically significant, indicating homogeneity of variances $(p=.768)$. The independent-samples t-test was used to determine whether there was a significant difference in transformational leadership style scores between non-experienced students (defined as freshmen or sophomores in the LDP) and experienced students (defined as juniors or seniors in the LDP). Of the 161 respondents in the sample, 112 were classified as non-experienced, and 49 participants were classified as experienced.

Experienced students scored significantly higher than non-experienced students, $t(159)$ $=2.16, p=.032$, as shown in Figure 1, indicating that participants with higher experience were associated with higher transformational leadership scores. The average transformational leadership score of the experienced participants was higher $(M=4.18, S D=.06)$ than that of the non-experienced participants $(M=4.02, S D=.04)$. Thus, it was concluded that there is a significant difference between experienced and non-experienced students in terms of transformational leadership style scores.

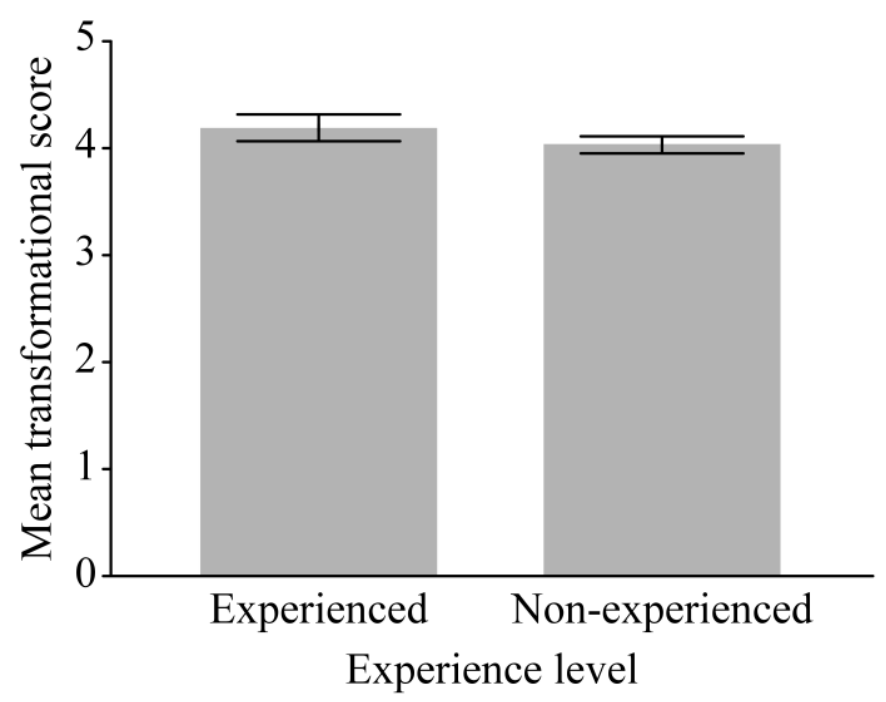

Figure 1. Comparison of means by experience levels in transformational score 
For the second test, a two-way ANOVA - with student leadership style and experience as independent variables and decision quality as the dependent variable - was conducted, and tests for violations of assumptions for the data were again conducted. A boxplot inspection was used to determine whether there were outliers for values greater than 1.5 box-lengths from the edge of the box and no outliers were indicated. Normality was assessed by examining the skewness and kurtosis z-scores of leadership styles (transformational and transactional) and experience (experienced, non-experienced), and the results revealed acceptable significance levels of 0.01 and were within $+2.58 \mathrm{z}$-score, thus indicating normality. Levene's test for equality of variances was used to assess homogeneity and homogeneity of variances, and the test was not statistically significant, $F(3,157)=.48, p=.696$.

To determine whether experience affects decision quality, the main effect of experience was examined. Participants' decision quality scores for experienced students $(M=3.74, S E=$ $0.87)$ were similar to the decision quality scores for non-experienced students $(M=3.70, S E=$ $0.83)$, as Figure 2 shows. These results showed that decision quality scores do not differ based on experience, and no statistically significant main effect was observed for experience level, $F(1$, $157)=.02, p=.876$. These results were not statistically significant at the 0.05 level, and it was concluded that there was no difference between non-experienced and experienced students with regard to decision quality.

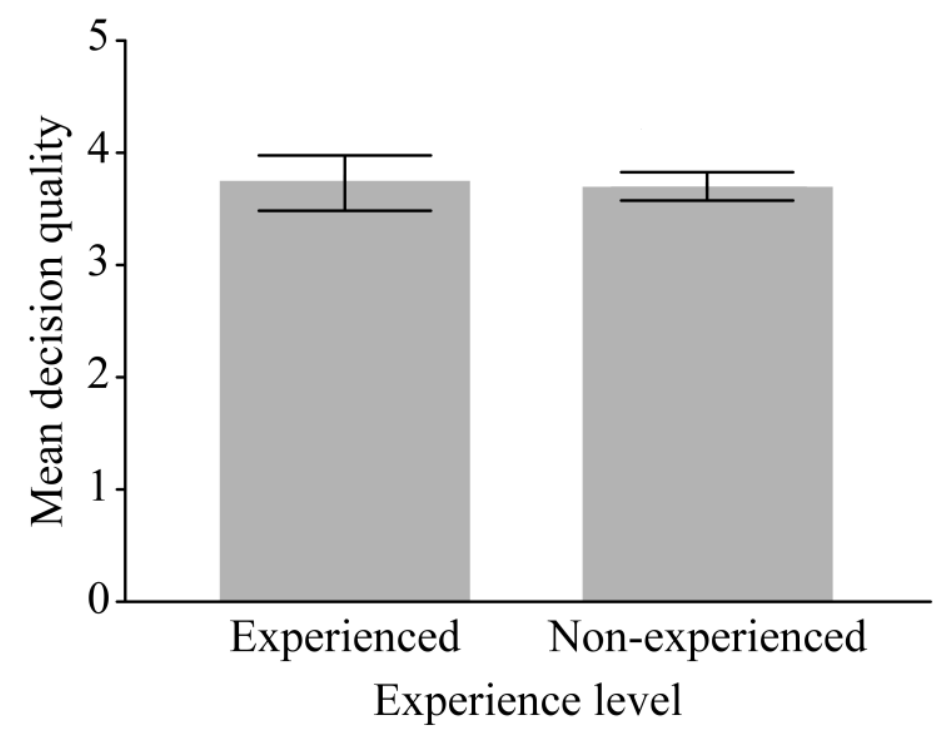

Figure 2. Comparison of mean decision quality scores by experience levels

To determine whether leadership style affects decision quality, the main effect of leadership style was examined. Decision quality scores for participants who exhibited transformational leadership style $(M=3.71, S E=0.83)$ were comparable to those for participants who exhibited transactional leadership style $(M=3.70, S E=0.87)$, as presented in Figure 3 . No statistically significant main effect was observed for leadership style, $F(1,157)=.00, \mathrm{p}=.965$. These results were not statistically significant at the 0.05 level; thus, it was shown that there was 
no difference between the transformational style group and the transactional style group with regard to decision quality.

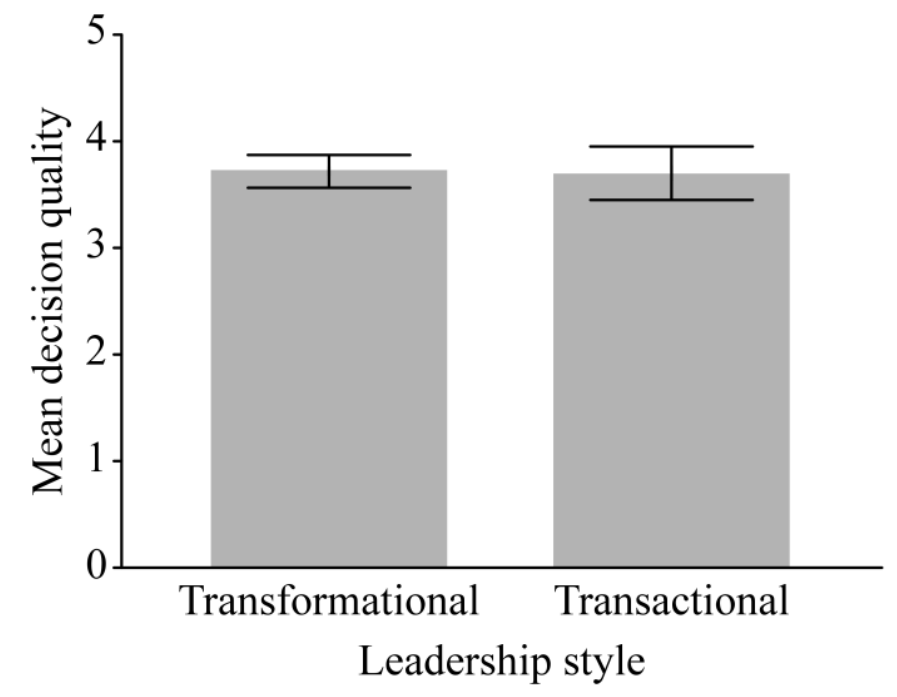

Figure 3. Comparison of mean decision quality scores by transformational and transactional style scores

To determine whether there was an interaction effect between leadership style and experience with regard to decision quality, a two-way ANOVA was conducted with experience and leadership style as independent variables and decision quality as the dependent variable, and the interaction effect was examined. Descriptive statistics for the decision quality of experienced and non-experienced students for transactional and transformational leader styles are presented in Table 1.

\section{Table 1}

Descriptive statistics for decision quality scores of experienced and non-experienced student leader styles

\begin{tabular}{llll}
\hline \multirow{2}{*}{ Experience Level } & Leadership Style & $M \quad$ Decision Quality Scores & \\
& & & $S D$ \\
\hline Experienced & Transformational & 3.74 & 0.89 \\
& Transactional & 3.72 & 0.81 \\
\hline Non-experienced & Transformational & 3.70 & 0.80 \\
& Transactional & 3.69 & 0.88 \\
\hline
\end{tabular}


The interaction effect of leadership style and experience level was found to be not significant, $F(1,157)=.00, \mathrm{p}=.975$. The decision scores of students with different leadership styles were not significantly different across experience levels. The results were not significant at the 0.05 level. Thus, it was shown that student experience does not significantly interact with student leadership style with regard to decision quality, as shown in Figure 4.

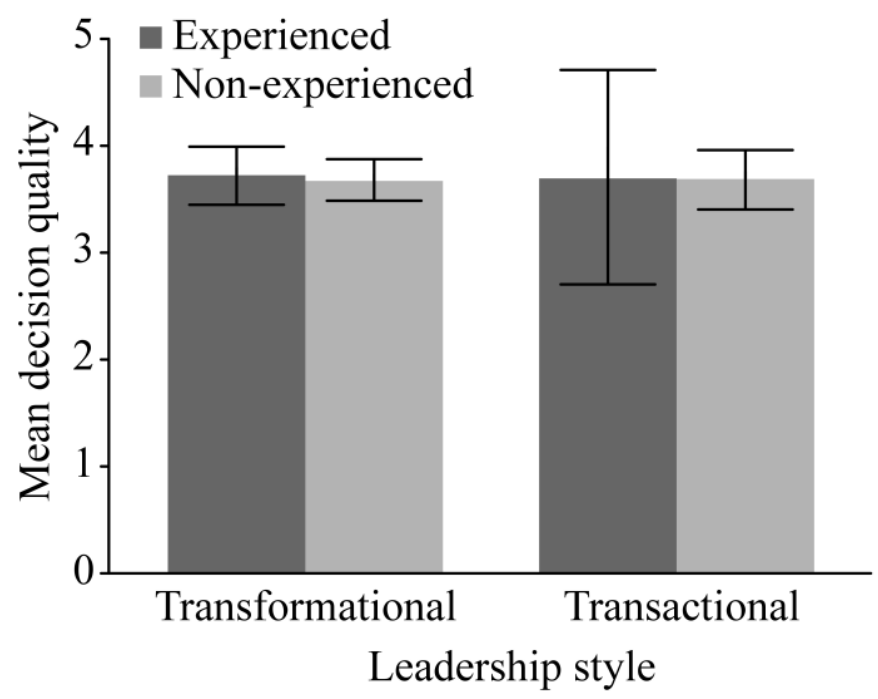

Figure 4. Comparison of means for decision quality based on leadership style and experience level

\section{Discussion}

The purpose of the present study was to assess the effects of leadership style and experience level on decision quality and to determine whether there was a significant difference between experienced and non-experienced students in terms of transformational leadership style scores. The results showed a significant difference in the leadership style scores between experienced and non-experienced students; experienced students showed significantly higher transformational leadership style scores. Upon initial review, the results did not indicate a significant main effect of leadership style and experience level on decision quality, and leadership style and experience level did not interact to have an effect on decision quality. Further review of the results showed that the decision quality scores were relatively high overall across the groups, which may indicate that leadership and decision training is effective in the LDPs of these seven universities and that students can achieve high decision quality regardless of their leadership style or experience. The notion that the shared curriculum of leadership development that is in use among the seven universities involved in the study may have had an impact in terms of where decision scores in the various groups would be high is notable because the curriculum and instruction used in the program may develop decision quality in a variety of students regardless of leadership style or experience and might therefore be used in a variety of university environments with some degree of success. Thus, the implications for theory and 
practice in leadership development are clear and further discussed here, and they should be considered by researchers, practitioners, and LDP supervisors and educators.

Experience and Leadership Style. The results from the present study are the first to confirm that more experience is positively related to greater transformational leadership style in students in an undergraduate LDP setting. The findings are important to inform our practice of leadership development and show that, as students acquire experience in an LDP, their transformational leadership increases and that a particular curriculum can be implemented that may foster higher transformational leadership. The LDP does not identify leadership style or focus specifically on developing transformational leadership. However, a focus on preferred leadership behaviors that are similar to transformational leadership components and the use of developmental experiences employed in the LDP curriculum may have been significant factors and certainly warrant further study and consideration. Experience is an important factor in the development and exploitation of leadership styles by students. More experienced students are able to identify and distinguish a greater number of leadership style options based on the preferred behaviors that are being evaluated in training scenarios (Popper \& Amit, 2009).

In the subject LDP, difficult scenario training is used to provide developmental experiences for students to learn and gain experience. The example of difficult interactions with the business or political leader of another culture is often used with actors in a realistic training environment. A student who uses a certain leadership style and who has limited experiences may not have the same level of effectiveness in a cultural training scenario that a more experienced student may have. Thus, the experienced student is more likely to select a superior option when making a key decision in terms of interacting with an important representative in a cultural training scenario. These findings imply that the current undergraduate LDP curriculum should not be changed. As a part of the training and curriculum, the experienced students in the study had participated in seven or more difficult scenario experiences in which they were evaluated and given feedback by instructors and senior and other more experienced students who had previously been through the scenario. The curriculum may explain the results of significantly higher transformational leadership style scores in the more experienced students in the LDP, as they are required to serve in training positions to emulate - and to be evaluated in the leadership role that they will assume after graduation. In addition, the experienced students must participate and are evaluated in the scenario training at a supervisory level. In their role as leader, these experienced students are also required to supervise and counsel the more junior students with less experience.

Experienced students had received evaluations and feedback prior to the study on preferred leadership behaviors and had been counseled and trained on their ability to influence others and to act as role models. The ability to influence others and to perform as role models corresponds to two components of transformational leadership: inspirational motivation (IM) and idealized attributes (IA) (Bass \& Bass, 2008). The focus and training on the preferred leadership behaviors and the training and focus in the scenarios is similar to those study results in which enhanced use of transformational leadership was stressed (Bass et al., 2003; Dvir et al., 2002; Hardy et al., 2010). The current study findings suggest that the LDP curriculum and the training provided to the students prior to the current study of structured experiences and assessments have been successful at developing leadership in the experienced third and fourth 
year students and that they should not be changed but should perhaps be expanded to provide the experience and evaluative capacity used by the experienced students to encompass the nonexperienced students at an earlier point in the LDP. Non-experienced students could acquire enhanced experience and the ability to use transformational leadership at an earlier point in the LDP, which might lead to increased performance by the student in later training scenarios. The potential for increased performance by expanding the LDP in this regard should be considered for pilot testing and assessment.

Higher Overall Decision Scores. This study had prominent strengths, including the use of a large sample size, stringent attention to analysis and control measures, and the use of the expert scoring methodology and multiple scenarios to improve reliability. In addition, variability was drastically reduced by using exclusion criteria and control measures established for students with advanced leadership training. The indications of overall high decision scores and higher use of transformational leadership styles in both experience level groups from the LDP might be explained by the need for additional wording changes to the SJT or because the sample drawn from the population was characterized by inordinately high levels of decision quality from training or previous experience. Rigorous steps were taken to ensure validity using a consensus of experts to establish the scoring of the SJTs and the exclusion criteria, and the delimitations of the study were well defined.

However, given the amount of training and focused effort in this study by stakeholders in the LDP toward the program outcomes and based on the curriculum, the more likely indication is that the results provide evidence of an important training effect from that the leadership curriculum and decision training received prior to the study. The population of students described were subject to a rigorous regimen in a well-designed LDP curriculum spanning a large multi-state area that may be using a successful and grounded practical approach to establishing strong leader traits and behaviors in the earliest stages of leadership formation. Students with transactional leadership style in the study may have relied upon behaviors that are more transformational - as learned in training prior to the study - to make decisions in the SJTs, even when the behaviors were not aligned with their leadership style. Further study and validation is recommended prior to any potential changes in the application of the LDP curriculum, assuming that the recommendation is followed to expand the experience level curriculum to non-experienced students. However, these findings are intriguing when considering the facets and application of the curriculum in the described programs and their potential applicability to other LDPs.

Leadership Styles. Together with the findings regarding higher transformational leadership in the experienced group, the overall high decision quality scores might have indicated that the training was successful at developing decision quality in both leadership style groups. A key performance outcome of training is to improve the ability of participants in the LDP, and the results highlight the fact that the emphasis on training leader behaviors should be continued. Thus, the students who participate in an LDP curriculum may be successful regardless of whether they embody transformational or transactional leadership styles in such an LDP. 
Decision Quality and Decision Process Models. Students received basic overview training in decision process models and were instructed in the classroom regarding how to implement the models in a basic classroom scenario or in a planning scenario to organize for a potential crisis decision. Later, the students were required to use the decision process in a laboratory environment with actors and other students who play various roles to provide a challenging environment, as the student must be tested in a leadership role. Students in the first and second year of the LDP had received introductory training as a normal part of the curriculum, whereas students in the third and fourth year of the LDP had received more advanced training and had several opportunities to practice and perform the steps of the approaches. Although the decision approaches can be difficult to understand and applying the use of these approaches in training should be maintained in the current form, the findings indicate that there are high levels of decision quality in all groups that are derived from using these decision approaches in practice scenarios.

Role Modeling. The feedback and assessment provided to the students in the LDP as they practiced and learned and performed duties similar to those they would perform after graduation may have contributed to their overall high performance. Further, the more that experienced students and instructors in the LDP emphasize and mentor and provide effective role models for less experienced students is important for a number of reasons. A formal written evaluation is provided when a student has performed their duties in a leadership position, and the evaluation can be written by either a senior experienced student serving in a senior leadership training position or by an instructor with a number of years of experience in the role as a leader. As with the IAs of transformational leadership, the students in years two, three, and four of the LDP are consistently exposed to role models in successive and overlapping roles to emulate in their practice roles as they progress in the LDP each year. The fourth-year students are the senior leaders of the organization and are supervised by the instructors in nominated positions in which the students are required to perform duties and emulate the position in the training organization. They in turn supervise the third-year students and are required to counsel and mentor them in their role. A key preferred behavior that is emphasized is the ability of leaders to inspire and influence others, which is similar to the IM component of transformational leadership (Bass, 1985). The levels of practice, mentorship, and feedback in such an environment would be substantive and could very well have contributed to the findings in which such high overall decision quality was noted in both leadership style groups and both experience level groups. Our findings contribute to the literature on leadership development, situational judgment, and transformational leadership by advancing our understanding of decision quality, experience, and leadership style in leadership development and also by enhancing our knowledge of the use of SJTs in leadership development. The significantly higher transformational leadership scores of the experienced students contribute to the literature and our knowledge of how transformational leadership may differ with experience.

\section{Conclusions}

In summary, we investigated the effects of leadership style and student experience level on decision quality during a formative period of participation in an undergraduate LDP. We also examined the differences in transformational leadership style and experience. Our results showed that greater experience was positively related to increased transformational leadership 
style and that high overall decision scores were indicated in all groups of students with varying leadership styles and varying experience levels and decision abilities. The high overall decision scores should be carefully considered and might be viewed as a substantial successful result of implementing a leadership development curriculum applied and used by seven universities in a multi-state LDP. This study was the first to show a significant relationship between experience and transformational leadership style in students in an undergraduate LDP using SJTs. Applicable curriculum and other techniques currently in use should be maintained in their present form. However, consideration should also be given to using additional developmental experiences and the curriculum of third and fourth year students earlier in the program in the first or second year to gain additional experience prior to assuming actual duties. Further research in this area should be conducted to examine even Larger LDPs in other geographical areas as well as other forms of LDP programs. In addition, the use of developmental experiences and preferred leadership behaviors in the LDP curriculum may have been a significant factor that warrants further study and consideration.

\section{References}

Ahn, M. J., Ettner, L. W., \& Loupin, A. (2011). From classical to contemporary leadership challenges. Journal of Leadership Studies, 5(1), 6-22. doi:10.1002/jls.20201.

Avolio, B. J., Walumbwa, F. O., \& Weber, T. J. (2009). Leadership: Current theories, research, and future directions. Annual Review of Psychology, 60, 421-449. doi:10.1146/annurev.psych.60.110707.163621.

Bass, B. M., \& Avolio, B. J. (2000). Platoon readiness as a function of leadership, platoon, and company cultures. http://handle.dtic.mil/100.2/ADA382244. (Technical Report 1104). Alexandria, VA: U.S: Army Research Institute for the Behavioral and Social Sciences.

Bass, B. M., \& Avolio, B. J. (2004). Multifactor leadership questionnaire (MLQ-form 5X): Manual and sampler set. Redwood City, CA: Mind Garden.

Bass, B. M., Avolio, B. J., Jung, D. I., \& Berson, Y. (2003). Predicting unit performance by assessing transformational and transactional leadership. Journal of Applied Psychology, 88(2), 207-218. doi:10.1037/0021.

Bass, B. M., \& Bass, R. (2008), The Bass handbook of leadership: Theory, research, and managerial applications (4th edn.). New York, NY: Free Press.

Bass, B. M. (1985), Leadership and performance beyond expectations. New York, NY: Free Press. Bass, B. M. (1998), Transformational leadership: Industrial, military, and educational impact. Mahwah, NJ: Lawrence Erlbaum Associates.

Brocato, B., Jelen, J., Schmidt, T., \& Gold, S. (2011). Leadership conceptual ambiguities. Journal of Leadership Studies, 5(1), 35-50. doi:10.1002/jls.20203. 
Brungardt, C. (1997). The making of leaders: A review of the research in leadership development and education. Journal of Leadership \& Organizational Studies, 3(3), 8195. doi:10.1177/107179199700300309.

Brungardt, C., Greenleaf, J., Brungardt, C, \& Arensdorf, J. (2006) Majoring in leadership: A review of undergraduate leadership degree programs. Journal of Leadership Education, 5(1), doi:10.12806/v5/i1/rf1

Davenport, B. (2014). From A to Google: How technology is impacting information and leadership. Journal of Leadership Studies, 8(2), 41-45. doi:10.1002/j1s.21329.

Dvir, T., Eden, D., Avolio, B. J., \& Shamir, B. (2002). Impact of transformational leadership on follower development and performance: A field experiment. Academy of Management Journal. Retrieved from http://www.jstor.org/stable/3069307, 45(4), 735-744. doi:10.2307/3069307.

Firing, K., Karlsdottir, R., \& Laberg, J. (2009). Social influence in military leadership training. Leadership \& Organization Development Journal, 30(8), 709-721. doi:10.1108/01437730911003885.

Foster, T. N., \& Farquharson, E. R. (2011). Assessment procedures for skills-based MBA courses adapted from the U.S. Army Reserve Officer Training Corps Leadership Development Program. Negotiation Journal, 27(3), 367-386. doi:10.1111/j.15719979.2011.00312.x.

Hannah, S. T., Campbell, D. J., \& Matthews, M. D. (2010). Advancing a research agenda for leadership in dangerous contexts [special issue]. Military Psychology, 22(Suppl. 1), S157-S189. doi:10.1080/0899560100364445.

Hardy, L., Arthur, C. A., Jones, G., Shariff, A., Munnoch, K., Isaacs, I., \& Allsopp, A. J. (2010). The relationship between transformational leadership behaviors, psychological, and training outcomes in elite military recruits. The Leadership Quarterly, 21(1), 20-32. doi:10.1016/j.leaqua.2009.10.002.

Hargis, M. B., Watt, J. D., \& Piotrowski, C. (2011). Developing leaders: Examining the role of transactional and transformational leadership across business contexts.Organization Development Journal. Retrieved from http://odinstitute.org, 29(3), 51-66.

Hauenstein, N. M. A., Findlay, R. A., \& McDonald, D. P. (2010). Using situational judgment tests to assess training effectiveness: Lessons learned evaluating military equal opportunity advisor trainees. Military Psychology, 22(3), 262-281. doi:10.1080/08995605.2010.492679.

Keating, K., Rosch, D., \& Burgoon, L. (2014). Developmental readiness for leadership: The differential effects of leadership courses on creating "ready, willing, and able" leaders. Journal of Leadership Education, 13(3), 1-16. doi:10.12806/V13/I3/RF1. 
Leonard, H. A., Polich, M., Peterson, J. D., Sortor, R. E., \& Moore, C. (2006), Something old, something new: Army leader development in a dynamic environment [electronic Book]. Arlington, VA: Rand Corporation.

Louvieris, P., Gregoriades, A., \& Garn, W. (2010). Assessing critical success factors for military decision support. Expert Systems with Applications, 37(12), 8229-8241. doi:10.1016/j.eswa.2010.05.062.

Mannheim, B., \& Halamish, H. (2008). Transformational leadership as related to team outcomes and contextual moderation. Leadership \& Organization Development Journal, 29(7), 617-630. doi:10.1108/01437730810906353.

McDaniel, M. A., Psotka, J., Legree, P. J., Yost, A. P., \& Weekley, J. A. (2011). Toward an understanding of situational judgment item validity and group differences.Journal of Applied Psychology, 96(2), 327-336. doi:10.1037/a0021983.

Ngaruiya, K. M., Velez, A. -L. K., Clerkin, R. M. \& Taylor, J. K. (2014). Public service motivation and institutional-occupational motivations among undergraduate students and ROTC cadets. Public Personnel Management, 43(4), 442-458. doi:10.1177/0091026014530270.

Ojiako, U., Johnson, J., Chipulu, M., \& Marshall, A. (2010). Unconventional competition drawing lessons from the military. Prometheus, 28(4), 327-342. doi:10.1080/08109028.2010.541756.

Olsen, O. K., Eid, J., \& Johnsen, B. H. (2006). Moral behavior and transformational leadership in Norwegian naval cadets. Military Psychology, 18(Suppl. 3), S37-S56. doi:10.1207/s15327876mp1803s_4.

Patrick, J., Scrase, G., Ahmed, A., \& Tombs, M. (2009). Effectiveness of instructor behaviours and their relationship to leadership. Journal of Occupational and Organizational Psychology, 82(3), 491-509. doi:10.1348/096317908X360693.

Pema, E., \& Mehay, S. (2012). Career effects of occupation-related vocational education: Evidence from the military's internal labor market. Economics of Education Review, 31(5), 680-693. doi:10.1016/j.econedurev.2012.04.005.

Peus, C., Braun, S., \& Frey, D. (2013). Situation-based measurement of the full range of leadership model - development and validation of a situational judgment test. The Leadership Quarterly, 24(5), 777-795. doi:10.1016/j.leaqua.2013.07.006.

Piccolo, R. F., \& Colquitt, J. A. (2006). Transformational leadership and job behaviors: The mediating role of Core Job characteristics. Academy of Management Journal, 49(2), 327340. doi:10.5465/AMJ.2006.20786079. 
Seiler, S., \& Pfister, A. C. (2009). "Why did I do this?": Understanding leadership behavior through a dynamic five-factor model of leadership. Journal of Leadership Studies, 3(3), 41-52. doi:10.1002/jls.20122.

Shepherd, R. S., \& Horner Jr., D. H. (2010). Indicators of leadership development in undergraduate military education. Journal of Leadership Studies, 4(2), 18-29. doi:10.1002/jls.20165.

Thomas, J. L., Dickson, M. W., \& Bliese, P. D. (2001). Values predicting leader performance in the U.S. Army reserve officer training corps assessment center: Evidence for a personality-mediated model. The Leadership Quarterly, 12(2), 181-196. doi:10.1016/S1048-9843(01)00071-6.

Tucker, J. S., Pleban, R. J., \& Gunther, K. M. (2009). The mediating effects of adaptive skill on values-performance relationships. Human Performance, 23(1), 81-99. doi:10.1080/08959280903400275.

Tucker, J. S., Gesselman, A. N., \& Johnson, V. (2010). Assessing leader cognitive skills with situational judgment tests: Construct validity results. (ARI Research Product 2010-04). Arlington, VA: U.S. Army Research Institute for the Behavioral and Social Sciences. http:// www.dtic.mil/cgi-bin/GetTRDoc? AD=ADA530102

van Schalkwyk, S. (2010). Early assessment: Using a university-wide student support initiative to effect real change. Teaching in Higher Education, 15(3), 299-310. doi:10.1080/13562511003740874

Walumbwa, F. O., Avolio, B. J., \& Zhu, W. (2008). How transformational leadership weaves its influence on individual job performance: The role of identification and efficacy beliefs. Personnel Psychology, 61(4), 793-825. doi:10.1111/j.1744-6570.2008.00131.x.

Wardynski, C., Lyle, D. S., \& Colarusso, M. J. (2010). Toward a U.S. Army officer corps strategy for success: Retaining talent. Officer corps strategy monograph series, Vol 1. Carlisle Barracks: U.S. Army War College, Strategic Studies Institute, (U413A66W273 2009). http://www.strategicstudiesinstitute.army.mil/pdffiles/PUB912.pdf.

West, C. (2012). Teaching leadership to undergraduates: Lessons from U. S. military colleges. Journal of College Teaching and Learning, 9(2). doi:10.19030/tlc.v9i2.6909

Westaby, J. D., Probst, T. M., \& Lee, B. C. (2010). Leadership decision-making: A behavioral reasoning theory analysis. The Leadership Quarterly, 21(3), 481-495. doi:10.1016/j.leaqua.2010.03.011.

Zhang, Z., \& Peterson, S. J. (2011). Advice networks in teams: The role of transformational leadership and members' core self-evaluations. Journal of Applied Psychology, 96(5), 1004-1017. doi:10.1037/a0023254. 


\section{Author Biographies}

Greg Grossman, DBA, is a lead faculty member for the Organizational Leadership Program and was selected to serve as a new faculty mentor and faculty development trainer at Colorado State University-Global Campus. He has over 25 years of experience in organizational leadership and has published a book on leadership experiences in the Middle East. He can be reached at gregory.grossman@ csuglobal.edu.

Ruth Sharf-Williams, PhD, is an Affiliate Professor in the School of Criminal Justice and Social Sciences at Tiffin University. She received her PhD in psychology with an emphasis on neuropsychology from The Graduate Center of the City University of New York in 2006. She can be reached at ruth.sharf@gmail.com. 